\title{
Better balancing the social and natural dimensions in sustainability research
}

\author{
Lennart Olsson $^{1}$ and Barry Ness ${ }^{1}$
}

\section{INTRODUCTION}

Judging from the state of affairs, calls for sustainable development over the last decades have largely fallen on deaf ears. Today, dire scientific warnings about the direction of the planet are more commonplace. Two recent examples have been warnings about "hothouse earth" (Steffen et al. 2018) and cautions about the sixth mass extinction (Ceballos et al. 2017). One factor contributing to this failure is the creation of more robust scientific knowledge on sustainability that can be used to understand societal processes and to coalesce society into action to address these pressing challenges. The task not only includes fostering more constructive dialogues between scientific community and society; it also comprises the production and exchange of knowledge that crosses the natural and the social sciences, especially including research that spans a more diverse range of social science perspectives. However, establishing these dialogues and research foci has proven to be a tall order given the increasing specialization of the academy, further solidified by entrenched positions in faculties and in individual disciplines.

Sustainability science has emerged over the past two decades as one promising research field to address the estrangement of scientific and social processes (Kates et al. 2001). The authors advocated and promoted advancing integrated research on sustainability issues through a set of seven core questions, including disparate areas such as interactions between nature and society in emerging models and conceptualizations, research to better define limits or boundaries to inform society about imminent degradation, and explorations of incentive structures that can guide societies toward more sustainable trajectories, among others.

The field has had many accomplishments. One notable recent realm of advancement, for example, has been in the area of collaborative, bottom-up processes and methods, integrating extra-academic knowledge into problem understanding and solution processes. This solutions-orientation has led to steady progress in experimentation through, e.g., urban living labs (Evans and Karvonen 2014), transition experiments (Luederitz et al. 2017), real-world experiments (Caniglia et al. 2017), and other similar transdisciplinary processes.

However, despite the field's many accomplishments, sustainability science has also fallen short of its potential. Much of the research in the field, for example, is carried out with little regard to the broader and more fundamental structures upholding society, often ignoring years of important advancements and insights located on other realms of the social sciences (Jerneck et al. 2011). It is therefore imperative that sustainability research simultaneously develop a critical agenda supported by vigorous research efforts that also question the framework of problemsolving efforts and research that poses more fundamental questions of how our present world order came about and how it might be in the process of change (Cox 1981) in order to avoid short-term fixes becoming the enemy of long-term solutions. Other aspects, including different ontological and epistemological perspectives, societal values, political interest and power, and social change in relation to resource use and environmental degradation also are essential in order to more robustly understand the problems and possible pathways to sustainable change.

\section{THE SPECIAL FEATURE}

We are pleased to introduce this Ecology and Society special feature on Integration of Social and Natural Dimensions of Sustainability. This collection of articles is based on the premise that there are varied views on what knowledge is: how it is developed and refined; how knowledge is tested; and how it is put into practice in different societal facets. It is an assemblage of eight research papers and one insight paper that are significantly the outcomes of the Linnaeus Centre ${ }^{[1]}$. Lund University Centre of Excellence for Integration of Social and Natural Dimensions of Sustainability (LUCID) program, a 10-year collaborative effort on sustainability research at Lund University to better integrate the natural and social sciences. The program was a bold effort to gather scholars at a number of academic levels to study different sustainability-relevant topics. It was a brave and bold attempt to develop interdisciplinarity and to build a platform for continuous pursuit of a more scientifically informed sustainability science. Challenges were primarily university structures and disciplinary identities. Much of the knowledge produced at LUCID throughout the past decade has been directed to a theoretical and methodological legacy in the field that can be characterized by methodological pluralism. Each of the contributions ${ }^{[2]}$ problematizes a specific realm in sustainability research and subsequently offers deeper insights into the area and possible alternatives for exploring them. Conversely, a few of the articles explore the research environments where sustainability science is carried out and offer suggestions for improvement for scholars at different levels working in the field.

\section{THE ARTICLES}

The first contribution of the special feature, "Social fields and natural systems: integrating knowledge about society and nature," by Olsson and Jerneck (2018), goes to the heart of the special feature. The authors suggest a combined approach to sustainability research called social fields and natural systems. The combined approach builds on social field theory from sociology and systems thinking and has the ability to assist sustainability scientists by integrating the best available knowledge from the natural sciences with knowledge from the social sciences. The scholars promote both theoretical and methodological pluralism as a way to overcome incommensurability between the natural and the social sciences while avoiding functionalism, technological and environmental determinism, 
and the over-reliance on rational choice theory. To strengthen their proposal, the authors illustrate two salient examples: climate change adaptation and geoengineering.

The subsequent paper, "The interdisciplinary decision problem: Popperian optimism and Kuhnian pessimism in forestry," by Persson et al. (2018a), examines ontological and epistemological differences that are often a barrier to integration in interdisciplinary fields such as sustainability science. By examining forest science as an example of an interdisciplinary field, the authors identify a fundamental type of interdisciplinary decision problem and examine the extent to which the problem might highlight particular challenges in interdisciplinary forest science and beyond.

Next, "A critical realist inquiry in conducting interdisciplinary research: an analysis of LUCID examples," by Nastar and colleagues (2018), is an exploration of research strategies to promote interdisciplinarity. It starts from a recognition that the scale and complexity of sustainability challenges necessitates a plurality of different social science perspectives to be incorporated in research. It shows how critical realism is a suitable ontological approach for pluralism in sustainability research. They then move to an analysis of the process and outcomes of LUCID, which maintains a heavy emphasis on incorporating social sciences into interdisciplinary sustainability research. By highlighting the need to systematically incorporate these essential elements into the research process, the authors stress the importance of an institutional setting to provide a conducive intellectual environment where authentic interdisciplinarity can emerge.

Persson and colleagues (2018b) also go to the core of this special feature. In their article entitled "Toward an alternative dialogue between the social and natural sciences," the authors explore two broad approaches in interdisciplinarity: unification and pluralism. By comparing different fields in sustainability, the authors conclude that none of them alone manages to provide, in a satisfactory manner, an integrated understanding of sustainability. They conclude by arguing for pluralism and advocate complex ways of articulating divergent ontological assumptions in sustainability research.

The next article in the special feature, by Knaggård et al. (2018), is entitled "Finding an academic space: reflexivity among sustainability researchers." It focuses on reflexivity in inter- and transdisciplinary sustainability research. Through focus group results from three groups of LUCID scholars, they find that the sustainability researchers, in divergent ways, experience reflexivity. They find that reflexivity about these issues seems to be crucial for how sustainability researchers construct a space for themselves within the academic system. One of the most important findings of the article is that $\mathrm{PhD}$ graduates are deeply reflexive about academic boundaries and how this awareness enables them to construct an academic identity that extends beyond conventional boundaries.

"Harnessing local knowledge for scientific knowledge production: challenges and pitfalls within evidence-based sustainability studies," by Persson, Johansson, and Olsson $(2018 c)$, explores limitations in the present interest of evidencebased sustainability studies and the epistemological challenges of incorporating practical knowledge and experience into the research process. The authors draw on examples from research in the Global South to suggest principles, such as problem-feeding, for harnessing practical experience for scientific knowledge production within sustainability studies.

The article, "At the nexus of problem solving and critical research," by Mahmoud et al. (2018), delves into the distinction between critical and problem-solving sustainability research. Through the analyses of a collection of interdisciplinary $\mathrm{PhD}$ theses that engage in critical and problem-solving sustainability research, the article shows how combining both approaches can emphasize that integrated understandings of humanenvironmental dynamics better facilitate multiscalar approaches, theoretical and methodological pluralism, and a combination of natural and social science theory.

"Ecosystem services between integration and economics imperialism," by Thorén and Stålhammar (2018), looks at the interdisciplinary merits of the ecosystem services concept through the lens of economics imperialism. The authors analyze a number of the critiques that have been raised with the concept, and the implications for fostering an interdisciplinary ecosystem services science.

The special feature's insight article, "Preparing the next generation of sustainability scientists," by Killion et al. (2018), takes a look at the deficiencies in current, integrative sustainability science education programs that are designed to foster inter- and transdisciplinary research. The article presents perspectives from a group of doctoral students that faced common barriers conducting integrative research, including, insufficient exposure to epistemological frameworks and team-science skills, challenges in effectively integrating diverse stakeholder perspectives into the research, and differing levels of committee support to conduct integrative research. To overcome the barriers and advance integrative research, the paper recommends how training opportunities can be better embedded within existing graduate programs.

${ }^{[1]}$ The main purposes of Linnaeus grants were to create, reinforce, maintain, and uphold internationally leading research environments, and to strengthen the ability of higher education institutions to make strategic prioritizations and to profile their research. The investment was also expected to result in structural effects on the research system. The LUCID Linnaeus Centre was funded by the Swedish Research Council Formas.

${ }^{[2]}$ About 500 scientific publications were published, of which 30 were $\mathrm{PhD}$ dissertations.

Responses to this article can be read online at: http://www.ecologyandsociety.org/issues/responses. php/11224

\section{LITERATURE CITED}

Caniglia, G., N. Schäpke, D. L. Lang, D. J. Abson, C. Luederitz, A. Wiek, M. D. Laubichler, F. Gralla, and H. von Wehrden. 2017. 
Experiments and evidence in sustainability science: a typology. Journal of Cleaner Production 169:39-47. https://doi.org/10.1016/ j.jclepro.2017.05.164

Ceballos, G., P. R. Ehrlich, and R. Dirzo. 2017. Biological annihilation via the ongoing sixth mass extinction signaled by vertebrate population losses and declines. Proceedings of the National Academy of Sciences of the USA 114(30):E6089-E6096. https://doi.org/10.1073/pnas. 1704949114

Cox, R. W. 1981. Social forces, states, and world orders: beyond international relations theory. Millennium 10(2):126-155. https:// doi.org/10.1177/03058298810100020501

Evans, J. and A. Karvonen. 2014. 'Give me a laboratory and I will lower your carbon footprint!' Urban laboratories and the governance of low-carbon futures. International Journal of Urban and Regional Research 38(2):413-430. https://doi.

org/10.1111/1468-2427.12077

Jerneck, A., L. Olsson, B. Ness, S. Anderberg, M. Baier, E. Clark, T. Hickler, A. Hornborg, A. Kronsell, E. Lövbrand, and J. Persson. 2011. Structuring sustainability science. Sustainability Science 6(1):69-82. https://doi.org/10.1007/s11625-010-0117-x

Kates, R. W., W. C. Clark, R. Corell, J. M. Hall, C. C. Jaeger, I. Lowe, J. J. McCarthy, H. J. Schellnhuber, B. Bolin, N. M. Dickson, S. Faucheux, G. C. Gallopin, A. Grübler, B. Huntley, J. Jäger, N. S. Jodha, R. E. Kasperson, A. Mabogunje, P. Matson, H. Mooney, B. Moore III, T. O'Riordan, and U. Svedin. 2001. Sustainability science. Science 292:641-642. https://doi.org/10.1126/science.1059386

Killion, A. K., K. Sterle, E. Bondank, J. Drabik, A. Bera, S. Alian, K. Goodrich, M. Hale, R. A. Myer, Q. Phung, A. M. Shew, and A. W. Thayer. 2018. Preparing the next generation of sustainability scientists. Ecology and Society 23(4):39. https://doi. org/10.5751/ES-10395-230439

Knaggård, Å., B. Ness, and D. Harnesk. 2018. Finding an academic space: reflexivity among sustainability researchers. Ecology and Society 23(4):20. https://doi.org/10.5751/ES-10505-230420

Luederitz, C., N. Schäpke, A. Wiek, D. J. Lang, M. Bergmann, J. J. Bos, S. Burch, A. Davies, J. Evans, A. König, M. A. Farrelly, N. Forrest, N. Frantzeskaki, R. B. Gibson, B. Kay, D. Loorbach, K. McCormick, O. Parodi, F. Rauschmayer, U. Schneidewind, M. Stauffacher, F. Stelzer, G. Trencher, J. Venjakob, P. J. Vergragt, H. von Wehrden, and F. R. Westley. 2017. Learning through evaluation: a tentative evaluative scheme for sustainability transition experiments. Journal of Cleaner Production 169:61-76. https://doi.org/10.1016/j.jclepro.2016.09.005

Mahmoud, Y., A. Jerneck, A. Kronsell, and K. Steen. 2018. At the nexus of problem-solving and critical research. Ecology and Society 23(4):40. https://doi.org/10.5751/ES-10458-230440

Nastar, M., C. S. Boda, and L. Olsson. 2018. A critical realist inquiry in conducting interdisciplinary research: an analysis of LUCID examples. Ecology and Society 23(3):41. https://doi. org/10.5751/ES-10218-230341

Olsson, L., and A. Jerneck. 2018. Social fields and natural systems: integrating knowledge about society and nature. Ecology and Society 23(3):26. https://doi.org/10.5751/ES-10333-230326
Persson, J., A. Hornborg, L. Olsson, and H. Thorén. $2018 b$. Toward an alternative dialogue between the social and natural sciences. Ecology and Society 23(4):14. https://doi.org/10.5751/ ES-10498-230414

Persson, J., E. L. Johansson, and L. Olsson. 2018c. Harnessing local knowledge for scientific knowledge production: challenges and pitfalls within evidence-based sustainability studies. Ecology and Society 23(4):38. https://doi.org/10.5751/ES-10608-230438

Persson, J., H. Thorén, and L. Olsson. 2018a. The interdisciplinary decision problem: Popperian optimism and Kuhnian pessimism in forestry. Ecology and Society 23(3):40. https://doi.org/10.5751/ES-10401-230340

Steffen, W., J. Rockström, K. Richardson, K., T. M. Lenton, C. Folke, D. Liverman, C. P. Summerhayes, A. D. Barnosky, S. E. Cornell, M. Crucifix, J. F. Donges, I. Fetzer, S. J. Lade, M. Scheffer, R. Winkelmann, and H. J. Schellnhuber. 2018. Trajectories of the Earth system in the Anthropocene. Proceedings of the National Academy of Sciences of the USA 115(33):8252-8259. https://doi. org/10.1073/pnas.1810141115

Thorén, H., and S. Stålhammar. 2018. Ecosystem services between integration and economics imperialism. Ecology and Society 23(4):44. https://doi.org/10.5751/ES-10520-230444 